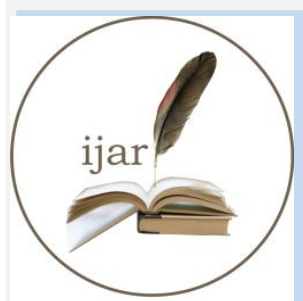

ISSN NO. 2320-5407
Journal Homepage: -www.journalijar.com INTERNATIONAL JOURNAL OF ADVANCED RESEARCH (IJAR)

Article DOI: $10.21474 / \mathrm{IJAR} 01 / 1370$

DOI URL: http://dx.doi.org/10.21474/IJAR01/1370
INTERNATIONAL JOURNAL OF ADVANCED RESEARCH (JJAR)

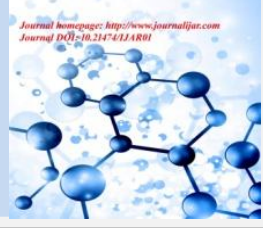

RESEARCH ARTICLE

\title{
MORPHOLOGICAL CHANGES IN (0 + 15):30:10:20:10:10 SMJ8 JEEWANU ON ADDING METHANOL AND AMMONIUM MOLYBDATE TO THE PEM OF THE JEEWANU BOTH BEFORE AND AFTER EXPOSURE TO SUNLIGHT UP TO A TOTAL OF 32 HOURS.
}

\author{
"Deepa Srivastava. \\ Department of Chemistry, S.S.Khanna Girls' Degree College, Constituent College of Allahabad University, \\ Allahabad, Uttar Pradesh, India.
}

\section{Manuscript Info}

Manuscript History

Received: 12 June 2016

Final Accepted: 22 July 2016

Published: August 2016

Key words:-

Jeewanu; Autopoetic; Eukaryote;SMJ8;

PEM;Sunlight

\section{Abstract}

Jeewanu, the autopoetic eukaryote is an example of molecular automata because of the formation of nucleic acid bases, sugars, amino acids, peptides and phospho lipids in these particles. Jeewanu shows reversible photochemical reduction of $\mathrm{Mo}^{6+}$ to $\mathrm{Mo}^{4+}$ and increase in the protons in sunlight and decrease in shade. The associated energy liberation is interesting because it could be utilized by the particles concerned for many reactions of metabolism in these particles. The mixture of methanol and acetic acid was selected because in this mixture big sized molybdenum Jeewanu with distinct morphology is formed. The spherical particles were observed after a total exposure of 9 hours. When the mixture was kept overnight, number of particles decreased. After 14 hours of exposure, smaller particles showed clear oscillatory motion. This motion stopped after 19 hours of exposure.

Copy Right, IJAR, 2016,. All rights reserved.

\section{Introduction:-}

As some molecular biologists opine, the theory of molecular automata most successfully describes the growth, reproduction and control of biological organization (Ingram, V.M., 1965).Sterilized aqueous mixture of ammonium molybdate, diammonium hydrogen phosphate, mineral solution and formaldehyde on exposure to artificial light results in the formation of self-sustaining coacervates. This may be another example of such molecular automata because of the formation of nucleic acid bases, sugars, amino acids, peptides and phospho lipids in these particles (Bahadur, K. and Ranganayaki, S., 1970). Jeewanu, the autopoetic eukaryote the model of protocell are formed by irradiation of above mixture to sunlight and a number of peptides have been detected in the photochemically formed peptides (Briggs, M.H., 1965). According to Cairns-Smith, the primitive genetic material had to hold stably a specific pattern which was the duplicating pattern and which could exert an influence on its surroundings specially encouraging its own propagation. Whenever growth and propagation, or duplication is considered, a source of energy is needed (Cairns-Smith, A.G., 1971). The source of energy for this process to begin with might have been sunlight as suggested by Abelson (Abelson, P.H., 1966).

Thus a system like Jeewanu became interesting because it shows reversible photochemical transformation. The aqueous mixture of SMJ8 are capable of reducing the $\mathrm{pH}$ on exposure to sunlight indicating the formation of protons and in shade the mixture shows increase in $\mathrm{pH}$ i.e. decrease in proton. This is also followed by the reduction of

Corresponding Author:-Deepa Srivastava.

Address:-Department of Chemistry, S.S.Khanna Girls' Degree College, Constituent College of 1612 Allahabad University, Allahabad, Uttar Pradesh, India. 
$\mathrm{Mo}^{6+}$ to $\mathrm{Mo}^{4+}$ in sunlight and oxidation of $\mathrm{Mo}^{4+}$ to $\mathrm{Mo}^{6+}$ in shade. The associated energy liberation is interesting because it could be utilized by the particles concerned for many reactions of metabolism in these particles.

The mixture of methanol and acetic acid was selected because it has been reported by Pradeep Kumar Verma(Verma, P.K., 1980)that in this mixture big sized molybdenum Jeewanu with distinct morphology is formed. Effect of variation in the concentration of mineral solution in the PEM of 1.531211SMJ38 before and after exposure to sunlight, on morphology of 1.531211SMJ38 was studied by Srivastava, D.(Srivastava, D.2016).

In this paper,an attempt is made to investigate the effect of addition of methanol and ammonium molybdate in the PEM of the $(0+15): 30: 10: 20: 10: 10$ SMJ8 Jeewanu on the morphological features of SMJ8 Jeewanu. The morphological features of $(0+15): 30: 10: 20: 10: 10$ SMJ8Jeewanu both before and after exposure was recorded up to a total of 32 hours. The period of exposure to sunlight was changed to 1 hour per day from typical exposure of 4 hours per day for the formation of Jeewanu to investigate as to what happens to the morphological features of the mixture during the exposure and when the mixture stands in shade in the partial darkness during the day when it is kept in the laboratory after exposure and then stands for the whole night in darkness before the next exposure of 1 hour of sunlight was given.

\section{Experimental:-}

1. The following solutions were prepared:

2. $4 \%(\mathrm{w} / \mathrm{v})$ ammonium molybdate

3. $3 \%(w / v)$ diammonium hydrogen phosphate

4. Mineral solution was prepared by mixing various minerals in appropriate proportions.

5. $36 \%$ formaldehyde

6. $3 \%(\mathrm{w} / \mathrm{v})$ sodium chloride

7. $5 \%(\mathrm{w} / \mathrm{v})$ water soluble sodium silicate

\section{Preparation of the PEM of Jeewanu:-}

One dry, clean and sterilized corning conical flask of $150 \mathrm{ml}$ capacity was taken. $15 \mathrm{ml}$ distilled water, $30 \mathrm{ml}$ diammonium hydrogen phosphate; $10 \mathrm{ml}$ mineral solution and $10 \mathrm{ml}$ sodium silicate were added in the flask. The total volume of the mixture was $95 \mathrm{ml}$.

The flask was cotton plugged, shaken well and exposed to sunlight for 8 hours giving 2 hours exposure daily for four days. Then after 8 hours exposure, $30 \mathrm{ml}$ of methanol was added and then after this, $15 \mathrm{ml}$ of ammonium molybdate was added. After this, the mixture was exposed to sunlight for total of 32 hours giving 1 hour exposure daily and the morphological features were recorded both before and after each exposure.

\section{Observations:-}

The observations made on the change in number and size in $\mu(\mathrm{SA} / \mathrm{view})$ of the Jeewanu $(0+$ 15):30:10:20:10:10SMJ8 where first figure in the bracket represents amount of ammonium molybdate and second figure represents the amount of distilled water in $\mathrm{ml}$ was recorded.(Table-1)

\section{Result and Discussions:-}

The microscopic observations show that particle formation did not occur in the PEM until ammonium molybdate was added when methanol and ammonium molybdate was added after 8 hours of exposure of the PEM; the spherical particles were observed after a total exposure of 9 hours. When the mixture was kept overnight, number of particles decreased. On exposure, again the number of the particles increased. The size of the particles usually decreased on giving a night gap. After 14 hours of exposure, smaller particles showed clear oscillatory motion. This motion stopped after 19 hours of exposure. It has further been observed that more particles were motile and also more clear motion was observed after a night gap before exposure and on exposure, the motion decreased and the number of motile particles.

The microscopic observations were discontinued after a total of 24 hours exposure because the number of the particles became negligible. Thus it can be concluded that the decrease in the $\mathrm{pH}$ of the PEM on exposure to sunlight is due to the release of more $\mathrm{H}^{+}$ions which are formed due to the water spitting capability of Jeewanu which are formed in the PEM on exposure to sunlight. In the shade and subsequent night, the proton is consumed either for the formation of the Jeewanu when more Jeewanu was observed in the morning before exposure to sunlight than after 
exposure, or the proton set free were utilized in the fixation of nitrogen as decrease in the pressure in the Warburg's flasks in the shade has been observed by a number of workers in our laboratory. (Mehta, R, 1984, Tondon, R, 1987, Mathur, V, 1989).

Table 1:- Effect of addition of $30 \mathrm{ml}$ methanol and $15 \mathrm{ml}$ ammonium molybdate in the PEM of $(0+15)$ : 30:10:20:10:10SMJ8 on the number and size in $\mu$ (SA/ view) of the particles before and exposure to sunlight.

\begin{tabular}{|c|c|c|c|c|}
\hline \multirow{2}{*}{$\begin{array}{l}\text { Total period of } \\
\text { exposure in hours }\end{array}$} & \multicolumn{2}{|l|}{ Before exposure } & \multicolumn{2}{|l|}{ After exposure } \\
\hline & $\begin{array}{l}\text { Number of the } \\
\text { particles (SA/view) }\end{array}$ & $\begin{array}{l}\text { Size of the particles } \\
\text { in } \mu \text { (SA/view) }\end{array}$ & $\begin{array}{l}\text { Number of the } \\
\text { particles (SA/view) }\end{array}$ & $\begin{array}{l}\text { Size of the particles } \\
\text { in } \mu \text { (SA/view) }\end{array}$ \\
\hline 9 & - & - & $27.6 \pm 1.96$ & $0.25 \pm 0.001$ \\
\hline 10 & $72.2 \pm 1.01$ & $0.25 \pm 0.007$ & $53.2 \pm 3.12$ & $0.50 \pm 0.008$ \\
\hline 11 & $92.8 \pm 1.650$ & $0.25 \pm 0.001$ & $21.2 \pm 0.600$ & $1.00 \pm 0.004$ \\
\hline 12 & $205.2 \pm 1.740$ & $0.25 \pm 0.006$ & $154.8 \pm 1.930$ & $1.00 \pm 0.013$ \\
\hline 13 & $168.4 \pm 1.320$ & $0.25 \pm 0.001$ & $56.6 \pm 2.220$ & $0.50 \pm 0.018$ \\
\hline 14 & $206.6 \pm 0.316$ & $0.25 \pm 0.008$ & $98.4 \pm 0.013$ & $0.50 \pm 0.006$ \\
\hline 15 & $244.8 \pm 0.014$ & $0.25 \pm 0.001$ & $56.4 \pm 0.1 ` 34$ & $0.50 \pm 0.014$ \\
\hline 16 & $125.1 \pm 0.038$ & $0.25 \pm 0.006$ & $98.6 \pm 0.018$ & $0.25 \pm 0.001$ \\
\hline 17 & $305.0 \pm 0.014$ & $0.25 \pm 0.008$ & $100.8 \pm 0.012$ & $0.50 \pm 0.002$ \\
\hline 18 & $128.4 \pm 0.008$ & $0.25 \pm 0.001$ & $52.6 \pm 0.034$ & $0.25 \pm 0.008$ \\
\hline 19 & $102.2 \pm 0.042$ & $0.25 \pm 0.008$ & $90.2 \pm 0.013$ & $0.25 \pm 0.006$ \\
\hline 20 & $312.6 \pm 0.014$ & $0.25 \pm 0.003$ & $153.4 \pm 0.016$ & $0.25 \pm 0.001$ \\
\hline 21 & $356.8 \pm 0.023$ & $0.25 \pm 0.001$ & $164.4 \pm 0.034$ & $0.25 \pm 0.008$ \\
\hline 22 & $500.6 \pm 0.14$ & $0.25 \pm 0.08$ & $258.0 \pm 0041$ & $0.25 \pm 0.001$ \\
\hline 23 & $292.4 \pm 0.018$ & $0.25 \pm 0.041$ & $102.4 \pm 0.016$ & $0.50 \pm 0.008$ \\
\hline 24 & $250.0 \pm 0.024$ & $0.25 \pm 0.001$ & $150.4 \pm 0.008$ & $0.25 \pm 0.001$ \\
\hline 25 & \multirow{4}{*}{\multicolumn{4}{|c|}{ NO MICROSCOPIC OBSERVATIONS DONE }} \\
\hline 26 & & & & \\
\hline 27 & & & & \\
\hline 28 & & & & \\
\hline
\end{tabular}

\section{References:-}

1. Abelson, P.H. (1966), Proc. Natl. Acad. Sci., U.S.A., 55, pp 1365.

2. Bahadur, K. and Ranganayaki, S. (1970), J. Brit. Interplanetary. Soc., Vol. 23(12), pp 813-829.

3. Briggs, M.H. (1965), Space Flight, 7(4), pp 129-131.

4. Cairns-Smith, A.G. (1971), "The Life Puzzle", Oliver and Boyd, Edinburgh, pp 69, 71, 81,116-127, 131.

5. Ingram, V.M., (1965), "The Biosynthesis of Macromolecules", Benjamin, New York.

6. Mathur, V. (1989), "Studies in the origin of Life", D.Phil. Thesis, Dept. of Chem. Univ. of Allahabad, Allahabad, India.

7. Mehta, R. (1984), "Study of the photolytic dissociation of water by Jeewanu, the Primitive Autotrophs", D.Phil. Thesis, Dept. of Chem. Univ. of Allahabad, Allahabad, India.

8. Srivastava. D., (2016), "Study of the Effect of Variation in the Concentration of Mineral Solution in the PEM of 1.531211SMJ 38 before and after Exposure to Sunlight, on Morphology of 1.531211 SMJ 38". Int J Recent Sci Res. 7(4), pp.10648-10651.

9. Tondon, R. (1987), "Studies in Molecular Evolution", D.Phil. Thesis, Dept. of Chem. Univ. of Allahabad, Allahabad, India.

10. Verma, P.K., (1980), "Cytological Studies of Photochemically formed Jeewanu, The Protocell”, D.Phil. Thesis, Dept. of Chemistry, Univ. of Allahabad, Allahabad, India. 